system is therefore needed if implementing US-tenosynovitis as an outcome measure in clinical trials. The Outcome Measures in Rheumatology (OMERACT) US group's tenosynovitis scoring system has a good single and multicenter intraand inter-observer agreement, whereas the sensitivity to change in a multicenter design has never been tested.

Furthermore, it is unknown whether low grade synovial hypertrophy without Doppler Signal represents true inflammation, i.e. can be eliminated by antiinflammatory therapy and is sensitive to change.

Objectives: The aim of this study was to test the sensitivity to change of the OMERACT US scoring system for tenosynovitis, including minimal signs of tenosynovitis, in a multicenter design in order to validate it as an outcome measure in RA multicenter clinical trials. Furthermore, to assess the association between US and health assessment questionnaire (HAQ) and Disease Activity Score 28 for joints (DAS28).

Methods: Forty-nine patients with established RA (duration $>1$ year) and 18 early RA patients ( $<1$ year) with US-verified tenosynovitis were recruited from six rheumatology outpatient clinics in four different countries, if they were scheduled for treatment intensification with synthetic and/or biological Disease Modifying Anti-Rheumatic Drug. Tenosynovitis was assessed at baseline, and at three and six months' follow-up, by GS and Doppler, using the semi-quantitative OMERACT scoring system. Furthermore, HAQ and DAS28 were assessed.

Results: At baseline tenosynovitis was most frequently found at the extensor carpi ulnaris and tibialis posterior tendons $(70.7 \%$ and $44.4 \%$, respectively). The overall GS score showed a statistically significant decrease from baseline median 5 (25th;75th percentile: $2 ; 7)$ to 6 months $0(0 ; 3)$ and the overall Doppler score decreased statistically significant from baseline $3(2 ; 6)$ to 6 months $0(0 ; 1)$, both with a $p<0.01$. Both $G S$ and Doppler showed high responsiveness $(S R M>0.9)$, as did HAQ and DAS28 (table 1). Among tendons with grey scale (GS) $=1 /$ Doppler $=0$, 36 of $39(92.3 \%)$ showed therapy-induced improvements. A change of $2.1(95 \%$ confidence interval: 1.2:14.9) and 2.1 (Cl: 1.1:13.2) in DAS28 corresponded to a change in GS and Doppler of 1 (both $p=0.02$ ) respectively, using a mixed-model for repeated measurement. However, no association between US and HAQ was found.

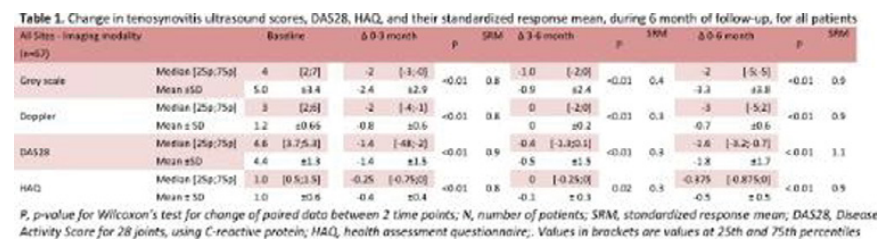

Conclusions: In conclusion, this RA multicenter study documented a high sensitivity to change of both GS and Doppler US tenosynovitis scores, indicating utility of the OMERACT US scoring system for diagnosing and monitoring tenosynovitis in multicenter trials. Secondly, synovial hypertrophy without Doppler signal, do respond to therapy, suggesting it reflects true inflammation. Finally, changes in US tenosynovitis scores are associated with changes in DAS28.

Disclosure of Interest: None declared

DOI: 10.1136/annrheumdis-2017-eular.1651

\section{OP0287 ULTRASONOGRAPHY-DETECTED PERIPHERAL ENTHESITIS IN PATIENTS WITH AXIAL SPONDYLOARTHRITIS - ANATOMICAL DISTRIBUTION, MORPHOLOGY AND RESPONSE TO ANTI-TNF THERAPY}

S. Seven, S.J. Pedersen, M. Østergaard, I.J. Sørensen, U.M. Døhn, S. Krabbe, L. Terslev. Copenhagen Center for Arthritis Research, Center for Rheumatology and Spine diseases, Rigshospitalet, Glostrup, Denmark

Background: Peripheral enthesitis (PE) is a characteristic feature of spondyloarthritis $(\mathrm{SpA})$ that may be asymptomatic and only detectable by imaging. Ultrasonography (US) has greater sensitivity than clinical examination for the detection of PE.[1]

Objectives: The aim of the study was to investigate the anatomical distribution, morphological abnormalities and response to anti-tumor necrosis factor (antiTNF) therapy of US-detected PE in patients with axial SpA (axSpA) initiating adalimumab (ADA)

Methods: In a randomized, placebo-controlled, double-blinded investigatorinitiated trial (NCT01029847), patients with axSpA according to the Assessment of SpA International Society (ASAS) criteria were randomized to subcutaneous ADA $40 \mathrm{mg}$ every other week (eow) or placebo from baseline to week 6 . From week 6 to 24, all patients received ADA $40 \mathrm{mg}$ eow. Of 49 patients enrolled, 21 participated in the US sub-study. US assessment applying the OMERACT US definitions for enthesitis[2] of 10 peripheral entheseal regions (Tables 1 \& 2) and clinical examination were performed at baseline, weeks 6 and 24. US was performed by an experienced investigator. Hypo-echogenicity, increased thickness and Doppler activity of the enthesis were considered signs of active inflammation, whereas insertional bone erosions, intratendinous calcifications and enthesophytes were regarded as signs of chronic lesions.[2]

Results: See tables.

Conclusions: In this axSpA cohort, US assessment primarily identified PE in the
Table 1. Distribution of US findings at baseline $(n=21)$

\begin{tabular}{lccc}
\hline Entheseal regions & $\begin{array}{c}\text { Enthesitis* }^{*} \\
\mathrm{~N}(\%)\end{array}$ & $\begin{array}{c}\text { Chronic lesions } \\
\mathrm{N}(\%)\end{array}$ & $\begin{array}{c}\text { Inflammation } \\
\mathrm{N}(\%)\end{array}$ \\
\hline Supraspinatus tendon & $6(29)$ & $6(29)$ & 0 \\
Triceps tendon & $2(10)$ & $1(5)$ & $1(5)$ \\
Common extensor, elbow & $5(24)$ & $5(24)$ & $1(5)$ \\
Common flexor, elbow & 0 & 0 & 0 \\
Greater femoral trochanter & $11(52)$ & $11(52)$ & 0 \\
Quadriceps tendon & $13(62)$ & $13(62)$ & $3(14)$ \\
Proximal insertion of the patellar tendon & $3(14)$ & $2(10)$ & $1(5)$ \\
Distal insertion of the patellar tendon & $3(14)$ & $2(10)$ & $2(10)$ \\
Achilles tendon & $17(81)$ & $16(76)$ & $4(19)$ \\
Plantar fascia & $4(19)$ & 0 & $4(19)$ \\
\hline
\end{tabular}

*inflammation and/or chronic lesions.

Table 2: US and clinical findings during study period

\begin{tabular}{|c|c|c|c|c|c|c|}
\hline & \multicolumn{3}{|c|}{ Placebo } & \multicolumn{3}{|c|}{ ADA } \\
\hline & $\begin{array}{l}\text { Week 0 } \\
(\mathrm{N}=10)\end{array}$ & $\begin{array}{l}\text { Week } 6 \\
(N=9)\end{array}$ & $\begin{array}{l}\text { Week } 24 \\
(N=10)\end{array}$ & $\begin{array}{l}\text { Week } 0 \\
(N=11)\end{array}$ & $\begin{array}{l}\text { Week 6 } \\
(N=11)\end{array}$ & $\begin{array}{l}\text { Week } 24 \\
(N=10)\end{array}$ \\
\hline \multicolumn{7}{|l|}{ US findings } \\
\hline Supraspinatus tendon & $3(30)$ & $2\langle 22\rangle$ & $1(10)$ & $3(27)$ & $2(18)$ & $1(10)$ \\
\hline Triceps tendon, elbow & $1(10)$ & 0 & $1(10)$ & $1(9)$ & 0 & $2(20)$ \\
\hline Common extensor, elbow & 0 & 0 & 0 & $5(46)^{*}$ & 0 & $1(10) \neq$ \\
\hline Common flexor, elbow & 0 & 0 & 0 & 0 & 0 & 0 \\
\hline $\begin{array}{l}\text { Greater femoral } \\
\text { trochanter }\end{array}$ & $6(60)$ & $6(67)$ & $6(60)$ & $5(46)$ & $6(55)$ & $6(60)$ \\
\hline Quadriceps tendon & $4(40)$ & $1(11)$ & $4(40)$ & $9(82)$ & $8(73)$ & $6(60)$ \\
\hline Proximal patellar tendon & $1(10)$ & 0 & 0 & $2(18)$ & $1(9)$ & $1(10)$ \\
\hline Distal patellar tendon & $2(20)$ & $1(11)$ & $1(10)$ & $1(9)$ & $1(9)$ & 0 \\
\hline Achilles tendon & $7(70)$ & $7(78)$ & $8(80)$ & $10(91)$ & $7(64)$ & $7(70)$ \\
\hline Plantar fascia & $1(10)$ & 0 & 0 & $3(27)$ & $3(27)$ & $2(20)$ \\
\hline \multicolumn{7}{|l|}{ Clinical findings } \\
\hline MASES & $4.6(4.0)$ & $4.0(3.3)$ & $2.2(3.7)$ & $3.0(3.7)$ & $2.1(2.5)$ & $2.0(3.0)$ \\
\hline LEI & $0.7(0.9)$ & $0.9(1.0)$ & $0.6(0.9)$ & $1.1(1.1)$ & $0.7(0.9)$ & $0.3(0.7)$ \\
\hline SPARCC Enthesitis Index & $3.2(3.8)$ & $3.6(2.6)$ & $2.2(2.8)$ & $2.6(2.9)$ & $1.6(1.9)+$ & $0.8(1.1)$ \\
\hline BASDAI & $7.0(1.9)$ & $6.4(2.5)$ & $4.3(2.7) \neq$ & $6.3(1.3)^{k}$ & $4.2(2.3) t$ & $2.9(2.5)$ \\
\hline \multicolumn{7}{|c|}{ 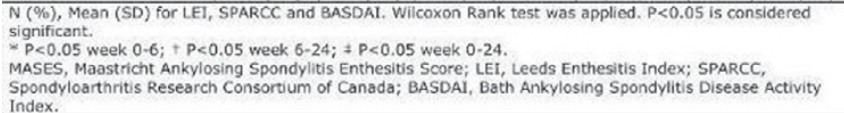 } \\
\hline
\end{tabular}

lower extremities, and predominantly chronic lesions. No change in chronic PE lesions were found during treatment indicating a low sensitivity to change of these lesions. The number of entheses with inflammatory activity was too low to detect any changes on US during ADA therapy.

References:

[1] D'Agostino MA, et al. Ann Rheum Dis 2011, 70(8):1433-1440.

[2] Terslev L, et al. Arthritis Care Res (Hoboken) 2014, 66(5):741-748.

Disclosure of Interest: None declared

DOI: 10.1136/annrheumdis-2017-eular.278

\section{OP0288 RELIABILITY OF A EULAR-OMERACT SEMIQUANTITATIVE SCORING SYSTEM FOR THE ASSESSMENT OF CARTILAGE IN RHEUMATOID ARTHRITIS}

$\underline{\text { P. Mandl }}^{1}$, E. Filippucci ${ }^{2}$, P. Studenic ${ }^{1}$, A. Bachta ${ }^{3}$, D. Bong ${ }^{4}$, G.A. Bruyn ${ }^{5}$,

C. Dejaco ${ }^{6}$, A. Delle Sedie ${ }^{7}$, C. Duftner ${ }^{8}$, I. Gessl ${ }^{1}$, H.B. Hammer ${ }^{9}$,

C. Hernandez Diaz ${ }^{10}$, A. lagnocco ${ }^{11}$, K. Ikeda ${ }^{12}$, D. Kane ${ }^{13}, \mathrm{H}$. Keen ${ }^{14}$

E. Kővári ${ }^{15}$, U. Moeller-Doehn ${ }^{16}$, E. Naredo ${ }^{17}$, J.-C. Nieto ${ }^{18}$, C. Pineda ${ }^{10}$,

A. Rodriguez ${ }^{19}$, W.A. Schmidt ${ }^{20}$, G. Supp ${ }^{1}$, L. Terslev ${ }^{16}$, R. Thiele ${ }^{21}$,

D. Windschall ${ }^{22}$, M.-A. D'Agostino ${ }^{23}$, P.V. Balint ${ }^{24}$. ${ }^{1}$ Medical University of Vienna,

Vienna, Austria; ${ }^{2}$ Università Politecnica delle Marche, Jesi, Italy; ${ }^{3}$ Military Institute of Medicine, Warsaw, Poland; ${ }^{4}$ Instituto Poal de Reumatologia, Barcelona, Spain;

${ }^{5}$ MC Groep, Lelystad, Netherlands; ${ }^{6}$ Medical University of Graz, Graz, Austria;

${ }^{7}$ University of Pisa, Pisa, Italy; ${ }^{8}$ Medical University of Innsbruck, Innsbruck,

Austria; ${ }^{9}$ Diakonhjemmet Hospital, Oslo, Norway; ${ }^{10}$ Instituto Nacional de

Rehabilitación, Mexico City, Mexico; ${ }^{11}$ Universitá degli Studi di Torino, Turin, Italy;

${ }^{12}$ Chiba University Hospital, Chiba, Japan; ${ }^{13}$ Trinity College Dublin, Dublin,

Ireland; ${ }^{14}$ University of Western Australia, Perth, Australia; ${ }^{15}$ Semmelweis

University, Budapest, Hungary; ${ }^{16}$ Copenhagen University Hospital Glostrup,

Copenhagen, Denmark; ${ }^{17}$ Hospital Universitario Fundación Jiménez Díaz and

Autónoma University; ${ }^{18}$ Hospital General Universitario Gregorio Marañón and

Complutense University; ${ }^{19}$ Hospital Ramón y Cajal, Madrid, Spain; ${ }^{20}$ Immanuel

Krankenhaus, Berlin, Germany; ${ }^{21}$ University of Rochester, Rochester, United

States; ${ }^{22}$ Asklepios Hospital, Weissenfels, Germany; ${ }^{23}$ Université VSQY, Inserm

U1173, APHP Ambroise Paré, Boulogne-Billancourt, France; ${ }^{24}$ National Institute of Rheumatology and Physiotherapy, Budapest, Hungary

Background: Joint destruction in rheumatoid arthritis (RA) is comprised of hyaline cartilage and bone damage, with the former more clearly associated with irreversible physical disability than bony damage.

Objectives: To test the reliability of a semiquantitative scoring system for the assessment of cartilage by musculoskeletal ultrasound (US) in a web-based exercise as well as a patient-based reliability study of patients with RA.

Methods: Static images of metacarpophalangeal (MCP) joints $2-5$ in RA patients and healthy controls were acquired and a dataset of 123 anonymized images including 25 duplicate images was circulated among an international EULAROMERACT taskforce of 25 rheumatologist experts in US who independently scored the images using a semiquantitative scoring system. Subsequently 12 taskforce members participated in a patient-based reliability study. During this 
meeting MCP joints $2-5$ of 6 patients with RA were assessed twice on the same day by all experts using US machines (GE) equipped with high-frequency transducers $(18-22 \mathrm{MHz})$ with presets calibrated for the appropriate assessment of cartilage. Participants assessed metacarpal cartilage both in the standardized longitudinal midline scan as well as by freehand technique utilizing multiple planes and scored by the semiquantitative scoring system. Intraobserver reliability was assessed by Cohen's kappa and interobserver reliability by Fleiss' kappa.

Results: The three-grade semiquantitative (Grade 0, normal cartilage; Grade 1, minimal change; Grade 2, severe change) scoring system demonstrated excellent (kappa: 0.87 ) to good (kappa: 0.73 ) intraobserver reliability in the webbased exercise and the patient-based reliability study respectively. Interobserver reliability was good in the web-based exercise (kappa: 0.64 ) and moderate (kappa: 0.49 ) in the patient-based reliability study. The dynamic technique performed slightly better than the longitudinal midline scan alone.

Conclusions: A semiquantitative scoring system demonstrated good intra- and moderate to good inter-observer reliability in a web-based exercise and patientbased reliability study. Our study demonstrates that US is a reliable tool for evaluating cartilage and supports the use of a new semiquantitative US scoring system for evaluating cartilage change in RA.

Acknowledgements: The patient-based reliability study was supported by a research grant from UCB.

Disclosure of Interest: None declared

DOI: 10.1136/annrheumdis-2017-eular.4314

\section{OP0289 TREAT-TO-TARGET IN EARLY RHEUMATOID ARTHRITIS: ASSOCIATION BETWEEN SUSTAINED REMISSION AND JOINT DAMAGE}

N.P. Sundlisater ${ }^{1}$, A.-B. Aga ${ }^{1}$, I.C. Olsen ${ }^{1}$, H.B. Hammer ${ }^{1}$, T. Uhlig ${ }^{1}$, D. van der Heijde $^{2}$, T.K. Kvien ${ }^{1}$, S. Lillegraven ${ }^{1}$, E.A. Haavardsholm ${ }^{1}$ on behalf of The Arctic study group. ${ }^{1}$ Diakonhjemmet Hospital, Oslo, Oslo, Norway; ${ }^{2}$ Leiden University Medical Center, Leiden, Netherlands

Background: Modern treatment of early RA is targeted towards remission. Sustained remission is viewed as more beneficial to the patient than remission at one time point, also with regards to inhibition of joint damage, $(1,2)$ but data are limited. Treat-to-target studies yielding high rates of sustained remission have improved the ability to assess the relationship between sustained remission and joint damage.

Objectives: To assess the frequency of no radiographic progression among early RA patients in sustained remission defined by established criteria and in patients with sustained absence of inflammation assessed by ultrasound.

Methods: RA patients with $<2$ years from first swollen joint who were DMARD naive with indication for DMARD treatment were included in the ARCTIC trial.(3) Patients in the ultrasound arm aiming for DAS $<1.6$, no swollen joints and no ultrasound power Doppler (PD) signal were included in the current analyses. Several definitions of sustained remission (12-24 months) were compared; DASESR, DAS28-ESR, SDAI, CDAI, ACR/EULAR Boolean remission (based on 44 joints), no swollen joints (44SJC), no ultrasound PD signal in any joint (0-96) and minimal total ultrasound greyscale (GS) score (defined as GS $\leq 2,0-96$ ). No radiographic progression (12-24 months) was defined as $<1$ unit change in the van der Heijde modified Sharp score (vdHSS). Positive and negative likelihood ratios of no radiographic progression were estimated for patients in sustained remission per definition.

Results: Of 103 patients, 76 (74\%) were female, mean [SD] age was 51.4 [12.9] years, disease duration 6.7 [5.3] months and DAS 3.5 [1.1]. The median [25th, 75th percentile] change in vdHSS $12-24$ months was $0.49[0.0,1.03]$, and $73(71 \%)$ patients had no radiographic progression. Sustained remission was reached by $23-61 \%$ according to the different criteria. Among patients in sustained remission, comparable proportions of patients did not progress radiographically across the

Table The performance of sustained remission 12-24 months for identifying patients without radiographic progression in the same time period. Significant likelihood ratios in bold.

\begin{tabular}{|c|c|c|c|c|}
\hline & \multirow{2}{*}{$\begin{array}{c}\text { Patients in } \\
\text { sustained } \\
\text { remission } \\
12-24 \text { months, } \\
\text { n(\%) }\end{array}$} & \multirow{2}{*}{$\begin{array}{c}\text { Patients in } \\
\text { sustained } \\
\text { remission and no } \\
\text { radiographic } \\
\text { progression 12- } \\
24 \text { months, n(\%) } \\
\end{array}$} & \multicolumn{2}{|c|}{$\begin{array}{l}\text { Likelihood ratios of no } \\
\text { radiographic progression } \\
12-24 \text { months }\end{array}$} \\
\hline & & & $\begin{array}{c}\mathrm{LR}+ \\
(95 \% \mathrm{CI}) \\
\end{array}$ & $\begin{array}{c}\text { LR- } \\
(95 \% \mathrm{CI}) \\
\end{array}$ \\
\hline \multicolumn{5}{|l|}{ Clinical outcomes } \\
\hline $\mathrm{DAS}<1.6$ & $46(45)$ & $37(80)$ & $\begin{array}{c}1.69 \\
(0.94,3.05)\end{array}$ & $\begin{array}{c}0.70 \\
(0.51,0.98)\end{array}$ \\
\hline DAS $28<2.6$ & $54(52)$ & $40(74)$ & $\begin{array}{c}1.17 \\
(0.76,1.82)\end{array}$ & $\begin{array}{c}0.85 \\
(0.56,1.29)\end{array}$ \\
\hline $\mathrm{SDAI} \leq 3.3$ & $33(32)$ & $26(79)$ & $\begin{array}{c}1.53 \\
(0.74,3.13)\end{array}$ & $\begin{array}{c}0.84 \\
(0.65,1.09)\end{array}$ \\
\hline $\mathrm{CDAl} \leq 2.8$ & $31(30)$ & $26(84)$ & $\begin{array}{c}2.14 \\
(0.91,5.04)\end{array}$ & $\begin{array}{c}0.77 \\
(0.61,0.98)\end{array}$ \\
\hline $\begin{array}{l}\text { ACR/EULAR Boolean } \\
\text { (based on } 44 \text { joints) }\end{array}$ & $24(23)$ & $18(75)$ & $\begin{array}{c}1.23 \\
(0.54,2.80)\end{array}$ & $\begin{array}{c}0.94 \\
(0.75,1.18)\end{array}$ \\
\hline $\begin{array}{l}\text { SJC44 } 0 \text {, } \\
\text { (range } 0-44 \text { ) }\end{array}$ & $50(49)$ & $39(78)$ & $\begin{array}{c}1.46 \\
(0.87,2.44)\end{array}$ & $\begin{array}{c}0.74 \\
(0.51,1.06)\end{array}$ \\
\hline \multicolumn{5}{|l|}{ Ultrasound } \\
\hline $\begin{array}{l}\mathrm{PD}=0, \\
\text { (range 0-96) }\end{array}$ & $63(61)$ & $51(81)$ & $\begin{array}{c}1.75 \\
(1.10,2.78)\end{array}$ & $\begin{array}{c}0.50 \\
(0.32,0.79)\end{array}$ \\
\hline $\begin{array}{l}\text { GS } \leq 2 \\
\text { (range 0-96) }\end{array}$ & $27(26)$ & $24(89)$ & $\begin{array}{c}3.29 \\
(1.07,10.10)\end{array}$ & $\begin{array}{c}0.75 \\
(0.61,0.91) \\
\end{array}$ \\
\hline
\end{tabular}

different criteria (74-89\%), with the most favorable result for minimal GS score (Table). Patients with sustained no PD or minimal GS score had an increased likelihood of no radiographic progression during the concurrent year (Table), but still rather weak to be useful in an individual patient. Based on the low LR+ none of the criteria identifies patients without radiographic progression very well; likewise, as the LR- is relatively high for all definitions, not being in remission does not change the probability of ongoing radiographic progression substantially.

Conclusions: In this treat-to-target early RA study, sustained remission rates were generally high and radiographic progression limited. None of the sustained remission criteria were able to exclude concurrent radiographic progression. Absence of ultrasound inflammation performed best of the definitions assessed. References:

[1] Aletaha D, et al. A\&R. 2009;60(5).

[2] Lillegraven S, et al. ARD. 2012;71(5)

[3] Haavardsholm EA, et al. BMJ. 2016;354.

Disclosure of Interest: N. Sundlisater: None declared, A.-B. Aga: None declared, I. Olsen: None declared, H. Hammer Consultant for: AbbVie, Pfizer, BMS, Roche, UCB, T. Uhlig: None declared, D. van der Heijde: None declared, T. Kvien: None declared, S. Lillegraven: None declared, E. Haavardsholm Grant/research support from: AbbVie, Pfizer, MSD, Roche, UCB

DOI: 10.1136/annrheumdis-2017-eular.2366

\section{OP0290 CORRELATION OF CXCL13 AND ULTRASSONOGRAPHIC FINDINGS OF JACCOUD ARTHROPATHY IN SYSTEMIC LUPUS ERYTHEMATOSUS}

D.S. Ribeiro ${ }^{1}$, C. Lins ${ }^{1}$, E. Pimenta ${ }^{1}$, V. Galvão ${ }^{1}$, W. Santos ${ }^{1}$, V. Machicado ${ }^{1}$, C. Baleeiro ${ }^{1}$, A. Pedreira ${ }^{1}$, A.P. Duque ${ }^{1}$, G. Rosa ${ }^{1}$, A. Atta ${ }^{2}$, I. Oliveira ${ }^{2}$, M. Santiago ${ }^{1}$. ${ }^{1}$ Escola Bahiana de Medicina e Saúde Pública; ${ }^{2}$ Faculdade de Farmácia, Universidade Federal da Bahia, Salvador, Brazil

Background: Joint involvement in systemic lupus erythematosus (SLE) is one of the earliest manifestation of the disease (1).Only $2-5 \%$ of the cases develop a deforming and non-erosive type of arthritis, known as Jaccoud Arthropathy (JA). Until now, there is no serum autoantibodies marker for it (2). The chemokine CXC ligand 13 protein $(\mathrm{CXCL} 13)$ is one of the most potent B-cell chemo attractants and is constitutively expressed in the B-cell follicles of secondary lymphoid organs (3). Its seric level has been associated to the degree of synovitis in patients with rheumatoid arthritis as studied by ultrasonography (US).

Objectives: To perform the first detailed US analysis of hands and wrists of SLE patients, with and without $\mathrm{JA}$, and to correlate those findings with the levels of CXCL13,other clinical and laboratory features and disease activity

Methods: 64 patients with SLE were included, being 32 with JA and 32 without JA paired by age and disease duration. The definition of JA was based on clinical criteria recently described by Santiago (4). Patients and controls underwent a highresolution US exam of wrists and hands. Synovial hypertrophy,tenosynovitis and erosions were evaluated according a semi-quantitative grading system according definitions provided by OMERACT (5). Serum concentrations of CXCL13 were quantified in both groups utilizing a commercially available kit. Autoantibodies such as antinuclear antibody (ANA), anti-dsDNA, anti-Sm, anti-SSA, anti-SSB were also tested. US findings were correlated with seric levels of CXCL13, other serological parameters and SLEDAI score.

Results: In the JA group, the mean age was 46.2 years and the mean duration of the disease was 17.3 years. Synovitis on US was found in 25 patients and tenosynovitis in 14. All of these findings were more frequent in SLE with JA, particularly tenosynovitis with difference statistically significant $(p=0.002)$. In JA patients the median levels of CXCL13 was $23.21 \mathrm{pg} / \mathrm{ml}$ as compared to 11.48 $\mathrm{pg} / \mathrm{ml}$ in SLE without JA group $(\mathrm{p}=0.08)$. There was an association between tenosynovitis and higher levels of CXCL13 in the JA group $(p=0.026)$. Patients with active disease were more common in the JA group $(p=0.004)$ and had increased serum levels of CXCL13 compared to patients with disease inactive $(p=0.008)$.

Conclusions: In conclusion, the present study is one of a few to describe US findings in SLE patients with JA and it confirms that synovitis and tenosynovitis are common features in the majority of these patients. In addition, CXCL13 may be regarded as a biomarker for tendon inflammation in JA.

\section{References:}

[1] Messuti LZ, A. Joint Involvement in SLE: Controversy of RHUPUS. INTERNATIONAL TRENDS IN IMMUNITY. 2014;2(4):155-61.

[2] Galvao V, Atta AM, et al. Profile of autoantibodies in Jaccoud's arthropathy. Joint Bone Spine. 2009 Jul;76(4):356-60.

[3] Zheng B, Ozen Z, et al. CXCL13 neutralization reduces the severity of collagen-induced arthritis. Arthritis Rheum. 2005 Feb;52(2):620-6.

[4] Santiago MB. Jaccoud's arthropathy: proper classification criteria and treatment are still needed. Rheumatology intern. 2013 Nov;33(11):2953-4.

[5] Wakefield RJ. The OMERACT Ultrasound Group: status of current activities and research directions. The Journal of rheumatology. 2007 Apr;34(4):848-51.

Disclosure of Interest: None declared

DOI: 10.1136/annrheumdis-2017-eular.2998 